\title{
Enhancing Performance in Mathematics Through Motivation, Peer Assisted Learning, And Teaching Quality: The Mediating Role of Student Interest
}

\author{
Yarhands Dissou Arthur $^{1 *}$ (D), Courage Simon Kofi Dogbe ${ }^{2}$ (D), Samuel Kwesi Asiedu-Addo ${ }^{3}$ \\ ${ }^{1}$ Department of Mathematics Education, Akenten Appiah-Menka University of Skills Training and Entrepreneurial Development, \\ GHANA \\ 2 Department of Management Studies Education, Akenten Appiah-Menka University of Skills Training and Entrepreneurial \\ Development, GHANA \\ ${ }^{3}$ Department of Mathematics Education, University of Education, Winneba, GHANA
}

Received 4 November 2021 - Accepted 20 December 2021

\begin{abstract}
In the Sub-Saran Africa, mathematics is a key subject in the school curriculum and most countries consider it as must-pass subject to gain admission into tertiary institutions. This notwithstanding, students' performance in mathematics in a cause for concern. For example, the mathematics performance of Ghanaian students in 2021 West Africa Senior Secondary Certificate Examination (WASSCE), was lower than that of 2020. This indicates that the percentage of students to gain admission into the tertiary has reduced. This study therefore explored the role of motivation, peer assisted learning, quality of teaching and student interest on student performance in mathematics. The study design was a survey, with structured questionnaire being used for data collection. The population comprised of students pursuing their undergraduate degree at a public university in Ghana. Purposive and convenient sampling techniques were used in selecting 373 first year undergraduate students of Akenten Appiah-Menka University of Skills Training and Entrepreneurial Development (AAMUSTED), who studied on Kumasi campus. Data was gathered during lecture hours, after permissions were sought from the lecturers handling the classes at the time of data collection. The path analysis was by Structural Equation Modelling, by using Amos (v.23) software. It was concluded that students learning interest in mathematics partially mediated the relationships between mathematics learning motivation and performance in mathematics; as well as between mathematics teaching quality and performance in mathematics. The effect of peer assisted mathematics learning on performance in mathematics was however fully mediated by students learning interest in mathematics.
\end{abstract}

Keywords: mathematics performance, motivation, peer assisted learning, teaching quality

\section{INTRODUCTION}

In the Sub-Saran Africa, mathematics is a key subject in the school curriculum and most countries consider it as must-pass subject to gain admission into tertiary institutions (Abreh et al., 2018). However, over the years, mathematics has been one of the poorly performed subjects in the West Africa Senior Secondary Certificate Examination (WASSCE) (Abreh et al., 2018). Great effort has been initiated by school leaderships and educational stakeholders for the adoption of appropriate teaching and learning methods that stimulate learners' interest in mathematics to improve their performance and achievement. It has generated a great deal of academic interest in the area of mathematics education and educational studies in general (Arthur et al., 2017; Tosto et al., 2016; Zhang \& Wang, 2020). In recent times, some studies have sought to therefore present the antecedents of performance in mathematics (Surur, 2022; Syarifuddin \& Atweh, 2022). Among the antecedents of performance in mathematics, motivation has been the most identified variable in most studies.

For example, Habók et al. (2020) found self-related beliefs and motivation as determinants of performance

(c) 2022 by the authors; licensee Modestum. This article is an open access article distributed under the terms and conditions of the Creative Commons Attribution License (http://creativecommons.org/licenses/by/4.0/). 


\section{Contribution to the literature}

- Firstly, the study proposed student interest in learning mathematics to partially mediate the relationship between mathematics learning motivation and performance in mathematics.

- Secondly, the study proposed mathematics learning interest to fully mediate the relationship between peer assisted learning and mathematics learning motivation.

- Finally, the study proposed interest in learning mathematics to partially mediate the relationship between teaching quality (as perceived by students) and performance in mathematics.

in mathematics. Li et al. (2020) found motivation, peer relationships, and self-efficacy, as the contributing factors for performance in mathematics. In the study of Prast et al. (2018), perceived competence was the only motivational variable found to influence high achievement in mathematics. Pitsia et al. (2017) also identified instrumental motivation, self-efficacy, anxiety, and attitudes towards mathematics as determinants of performance in mathematics. Bringula et al. (2017) found that motivation and the nature of feedback from mobile-assisted learning application, were significant determinants of performance in mathematics. García et al. (2016) found that affectivemotivational variables brought the distinction between high and low performance in mathematics. Froiland and Davison (2016) identified parent and student perceptions, and motivation as determinants of performance in mathematics. Motivation, emotional support and self-efficacy were also identified by Skaalvik et al. (2015) as determinants of performance in mathematics. Detail assessment of these past studies point out that motivation to learning mathematics emanates from two main sources; intrinsic and extrinsic. Intrinsic motivation to learn mathematics focuses on activities resulting from self-satisfaction rather than by external incentives. Extrinsic motivation (also referred to as instrumental motivation) is also focuses on the external incentives to take an action. These are external rewards for a well-implemented task. In terms of students' learning, extrinsic motivation may arise from career aspiration and parental characteristics or promises. Extrinsic motivation is associated with the expected benefits of an action rather than an enthusiasm.

Other studies also presented some other determinants of performance in mathematics. Ersozlu et al. (2021) used a multi-group invariance analysis in exploring cross-cultural differences in mathematics anxiety. Hwang et al. (2021) established that mathematics performance among students was influenced by social regulation-based online learning strategy. Rockinson-Szapkiw and Wendt (2020), Alegre et al. (2019), and Thurston et al. (2020) identified that peer tutoring had a statistically significant influence on students' performance in mathematics. Zhang and Wang (2020) identified that self-efficacy, mathematics interest, and mathematics anxiety, influenced performance in mathematics. Dorfner et al. (2018), Lazarides and
Buchholz (2019), and Motegi and Oikawa (2019) found that instructional quality had a significant effect on performance in mathematics. Collaborative digital pen learning approach also significantly improved performance of students in mathematics (Huang et al., 2017). Hinnant-Crawford et al. (2016) identified selfregulation and co-regulation as determinants of performance in mathematics, which varied across ethnic culture. Perceived parental support was identified as a determinant for performance in mathematics (Dinkelmann \& Buff, 2016). Bezzina (2010) found that gender determined performance in mathematics.

With these studies, it is realized that the role of mathematics learning interest has been less emphasized. This present research thus contributes to existing literature by identifying the influence of mathematics learning interest in the relationships between mathematics learning motivation, peer assisted learning and mathematics teaching quality (representing independent variables) and performance in mathematics (being the dependent variable). General academic interest is found to enhance the cognitive development and learning skills of students (Lerkkanen et al., 2012), and this has been found to positively affect students' academic performance (Tosto et al., 2016). Student interest in mathematics results in increased effort in the study of mathematics, increased frequency in the study of mathematics, increased duration in the study of mathematics, and identification of innovative learning strategies (Korhonen et al., 2016). Student interest in mathematics enhances their desire to acquire mathematics knowledge, thereby enhancing mathematics performance (Reeve et al., 2015). Personality traits may also influence students' performance academic outcomes (Nauzeer \& Jaunky, 2021; Röllke et al., 2020).

The study made three main theoretical contributions. Firstly, the study proposed student interest in learning mathematics to mediate the relationship between mathematics learning motivation and performance in mathematics. That is, we expect that mathematics learning motivation will have an effect on the interest of students in mathematics, while student interest in mathematics will have effect on performance in mathematics. Secondly, the study proposed mathematics learning interest to mediate the relationship between peer assisted learning and 
mathematics learning motivation. That is, peer assisted learning will ignite students' interest in mathematics, while this student interest in mathematics will lead to high achievement in mathematics. Finally, the study proposed interest in learning mathematics to mediate the relationship between teaching quality (as perceived by students) and performance in mathematics. This implies that teaching quality will boost students' interest in mathematics, while interest in mathematics further leads to better performance in mathematics. This present study is essential, as it helps to understand the factors that predict performance in mathematics. Mathematics is one of the four elements of STEM (Science, Technology, Engineering, and Mathematics) education, which is the focus of many governments across the globe in this present dispensation. That notwithstanding, sound background in mathematics is essential for pursing any of the remaining three branches of STEM.

Based on these research gaps, the following hypotheses were set for the study:

H1: Mathematics learning motivation has a direct positive effect on performance in mathematics.

H2: Peer assisted mathematics learning has a direct positive effect on performance in mathematics.

H3: Mathematics teaching quality has a direct positive effect on performance in mathematics.

H4: Mathematics learning interest mediates the relationship between mathematics learning motivation and performance in mathematics.

H5: Mathematics learning interest mediates the relationship between peer assisted learning and performance in mathematics.

H6: Mathematics learning interest mediates the relationship between mathematics teaching quality and performance in mathematics.

Figure 1 presents the conceptual framework of the study.

\section{MATERIALS AND METHODS}

\section{Population, Sample, and Data Collection}

The study design was a survey, as this allowed quantitative data to be collected and analyzed quantitatively using descriptive and inferential statistics (Saunders et al., 2012), as was done in this study. The population of the study comprised of first-year undergraduate students of Akenten Appiah-Menka University of Skills Training and Entrepreneurial Development (AAMUSTED), numbering 6,000. The University of Education, Winneba - Kumasi and Mampong campuses, were granted autonomy and remained AAMUSTED. The study makes use of two sampling techniques, which were, purposive and convenience sampling techniques.

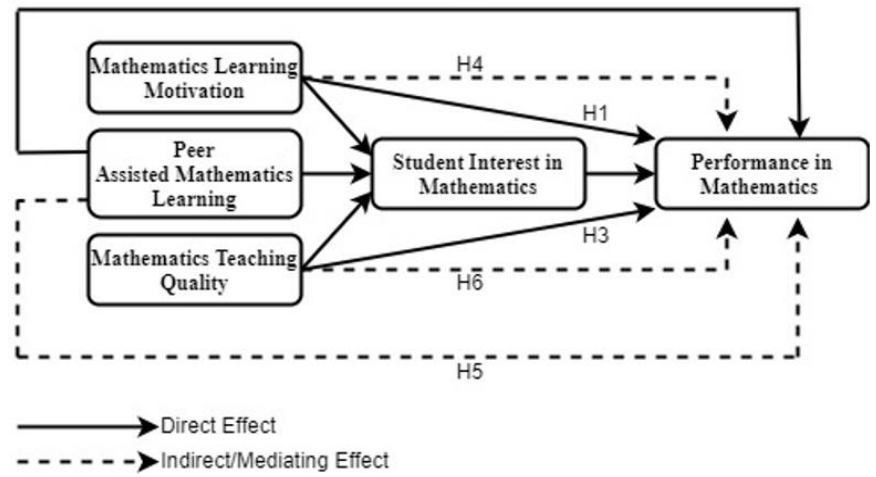

Figure 1. Conceptual framework

Although the study focused on AAMUSTED, the attention was on first year undergraduate students on Kumasi campus, thereby using purposive sampling technique. Purposive sampling technique was used to select students who studied, Information Technology, Construction and Wood Technology, Automotive Technology, Catering, Fashion Design, Business Administration, Electrical Technology, and Mechanical Technology. These were first degree students who had statistics or mathematics as part of their program of study irrespective.

Secondly, after purposively targeting these groups of students, convenient sampling technique was used in selecting students in these groups, who were readily available at lecture halls during the period of data collection. While purposive sampling helped in selecting sample group which are most relevant to the study, convenient sampling on the other hand helped in selecting the cases that are easiest to obtain from the sampling frame defined by the purposive sampling technique (Saunders et al., 2012).

The data was gathered during class hours, after permission was sought from the lecturers handling the courses at the time of data collection. The study made use of structured questionnaire, and data was gathered within a period of four weeks. The majority of the sampled students were aged between 18-25 years.

Miller and Brewer's (2003) approach to calculating sample size was adopted for this study. The formula is as follows:

$$
n=\frac{N}{1+N\left(\alpha^{2}\right)^{\prime}}
$$

where, $N=$ population (6000), $n=$ sample size, and $a=$ significant level (0.05).

Since the study focused on human respondents, whose response may be subject to biases, the calculation of the sample size was based on $95 \%$ confidence interval, with $5 \%$ margin of error.

From the formula, we have;

$$
\begin{gathered}
n=\frac{6000}{1+6000\left(0.05^{2}\right)^{\prime}} \\
n=\frac{\mathbf{6 0 0 0}}{\mathbf{1 6}}=375 .
\end{gathered}
$$


Although 375 was the ideal sample size, 373 questionnaires were considered usable, after the data collection process. This gave a response rate of $99.5 \%$ $\left[(373 / 375)^{\star} 100\right]$, which the researchers deemed as very reliable representation for the study. Before the main data collection exercise, an approval was sought from the university administration, and this was made known to the students who partook in the study.

\section{Measures and Questionnaire}

This research used one dependent variable (Performance in mathematics - ACHIEV), one mediator (Student Interest in Mathematics - INT), and three independent variables (Mathematics Learning Motivation - MOTI; Peer Assisted Learning - PEER; Mathematics Teaching Quality - QUAL). These five constructs were all responded to on a Likert scale weighted $1=$ Strongly Disagree, to $5=$ Strongly Agree. The measurement items for performance in mathematics were adapted from Zhou et al. (2020); those of students' mathematics learning interest were developed from Zhang and Wang (2020); those of mathematics learning motivation were developed from Prast et al. (2018), those of peer assisted mathematics learning were adapted from Thurston et al. (2020), and those of mathematics teaching quality were adapted from Diaconu-Gherasim et al. (2019). The measurement items, although picked from past studies, were edited to suit the present study. The study was also pilot tested, where ambiguous statements were reworded. The Cronbach's alpha scores for the constructs were calculated after the pilot study data was generated. The alpha score for mathematic learning motivation was 0.655 , that of mathematics learning was 0.597 , that of mathematics teaching quality was 0.701 , that of students' interest in mathematics was 0.667 , and that of performance in mathematics was 0.704 . The poor factor loadings for some of the constructs was because of the ambiguity in some of the statements (measurement items), which were identified through the pilot study, and corrected before the final questionnaire was used for the main data collection.

A key benefit of using pre-existing measurement scale for a study is that, it has been extensively tested in the past, and its reliability is enhanced. As indicated by Hyman et al. (2006), a validated questionnaire is most preferable when the environment of the validated questionnaire is similar to that of the new study environment. Using validated measurement scale also reduces the burden on researchers to develop and validity measurement scales on their own.

\section{Validity and Reliability Analysis}

This study runs Confirmatory Factor Analysis (CFA) using Amos (v.23) software, as done by past studies such as, Dogbe et al. (2020). The researchers adopted the CFA approach due its many advantages, as identified by
Lahey et al. (2012). Firstly, CFA allows statistical tests of multiple aspects of hypothesized models. Also, CFA provides statistical information about the degree and source of misfit models, which is used to modify the model further. Further, CFA calculates error variance distinctly from unexplained variance in the underlying constructs, leading to less measurement errors of latent variables compared to the regions of interests that define the network. Finally, CFA allows for comparison of competing models, by integrating data limitation in the analysis.

The results of CFA are indicated in Table 1. As part of the CFA procedure, observed variables with poor factor loading (less than 0.5), were deleted from further analysis. Originally, performance in mathematics had four measurement items (observed variables), students' mathematics interest had seven measurement items, mathematics learning motivation had six measurement items, peer assisted mathematics learning had seven measurement items, and mathematics teaching quality had eight measurement items. After the CFA process, all measurement items were retained for performance in mathematics and student interest in mathematics. Two (2) each observed variables were however deleted from mathematics learning motivation, and peer assisted learning dimensions, whiles three observed variables were removed from mathematics teaching quality.

Cronbach's alpha (CA) was also run to assess the internal consistency of the observed variables. The CA was calculated using SPSS (v.23), using the retained items. Reliability of the observed variables is said to be achieved when the CA score is at least 0.7. From the analysis presented in Table 1, it could be ascertained that the CA for all latent variables were higher than 0.7, which indicates internal consistency had been achieved. Mathematic Learning Motivation had CA score of 0.749, Peer Assisted Mathematics Learning had a CA score of 0.794, Mathematics Teaching Quality had a CA score of 0.813 , Students Interest in Mathematics had an alpha score 0.951 , and Performance in mathematics also had an alpha score of 0.760 .

Average Variance Extracted (AVE) was calculated, to assess the convergent validity of the observed variables. Convergent validity assesses how well the measurement items in the new scale, correlate with other measurement items on the same construct (Trochim \& Donnelly, 2001). Based on the Fornell and Larcker (1981) criteria, the least of AVE must be 0.5 , while that of composite reliability (CR) must also be 0.7, to conclude that convergent validity was achieved among the observed variables. The results indicate that 0.524 was the least (PEER), while 0.821 was the least $\mathrm{CR}$ (ACHIEV), suggesting this study achieved convergence validity.

As suggested by Hair et al. (2010), CMIN/DF should be less than 3, CFI and TLI should be at least 0.9, RMR and RMSEA should be at least 0.8 , while P-close should 
Table 1. Confirmatory factor analysis

Model fit indices: $\mathrm{CMIN}=710.358 ; \mathrm{DF}=249 ; \mathrm{CMIN} / \mathrm{DF}=2.853 ; \mathrm{TLI}=0.918 ; \mathrm{CFI}=0.915 ; \mathrm{RMSEA}=0.071$;

$\mathrm{RMR}=0.054 ; \mathrm{p}$-close $=0.071$

td. factor

Mathematics learning motivation (MOTI): $\mathrm{CA}=0.749 ; \mathrm{CR}=0.826 ; \mathrm{AVE}=0.543$

I often seek opportunities in attaining new skills in solving mathematical problems (MLM1) loading

I feel accomplished upon completing a task in mathematics (MLM2)

I am motivated to learn mathematics because it is need in all fields of life (MLM3)

0.755

I learn mathematics for personal accomplishment (MLM4)

Peer assisted mathematics learning (PEER): $\mathrm{CA}=0.794 ; \mathrm{CR}=0.845 ; \mathrm{AVE}=0.524$

0.700

I understand mathematics better during peer discussions (PAML1)

My course mates encourage me to learn mathematics during and after mathematics lessons (PAML2)

I look for other students for help whenever I encounter problems in working mathematics (PAML3)

I learn mathematics better during team project (PAML4)

I contribute effectively and my peer accepts my contribution during peer discussions in mathematics

Mathematics teaching quality (QUAL): $\mathrm{CA}=0.813 ; \mathrm{CR}=0.859 ; \mathrm{AVE}=0.551$

Teacher developing mathematical concepts systematically is quality of a good teacher (TMTQ1)

0.613

Teacher engages students in their free time improve quality of teaching and learning of mathematics

(TMTQ2)

Teachers give enough classroom exercises to practice to test my understanding of the concept being taught

(TMTQ3)

My teacher encourages me to learn mathematics (TMTQ4)

My mathematics teacher provides good feedback for better understanding (TMTQ5)

Students interest in mathematics (INT): $\mathrm{CA}=0.951 ; \mathrm{CR}=0.951 ; \mathrm{AVE}=0.737$

I have interest in learning mathematics as part of my course (SLIM1)

0.721

Mathematics is one of the courses I enjoy learning most (SLIM2)

0.737

0.755

The time I use learning mathematics is the time I enjoy most in my private studies (SLIM3)

0.912

Learning mathematics is interesting (SLIM4)

I love mathematics as a subject (SLIM5)

I always want to solve mathematics problems (SLIM6)

0.935

0.869

0.873

For me, learning mathematics is fun (SLIM7)

0.908

Performance in mathematics (ACHIEV): $\mathrm{CA}=0.760 ; \mathrm{CR}=0.821 ; \mathrm{AVE}=0.534$

Learning mathematics enhances my professional knowledge and concepts (MSA1)

0.771

Learning mathematics enhances my decision-making ability (MSA2)

Learning mathematics enhances my thinking ability (MSA3)

Learning mathematics enhances my analytical ability (MSA4)

0.755

0.713

0.681

CFI=Comparative Fit Index; CMIN/DF=Chi-Square/Degree of Freedom; RMR=Root Mean Square Residual; RMSEA=Root Mean Square Error of Approximation; TLI=Tukey-Lewis Index

also be greater than 0.05 . CMIN measures the minimum discrepancy in the model; RMR and RMSEA represent absolute fit indices, by assessing the deviation of a hypothesized model from a perfect model; while CFI and TLI represent incremental fit indices, by comparing how well the hypothesized model fits the baseline model (assessing the worst fit) (Xia \& Yang, 2019). The cutoff values for both CFI and TLI are based on normal-theory maximum likelihood with continuous data. P-close is also expected to be statistically insignificant at 5\% (greater than 0.05). P-close represents the $\mathrm{p}$-value for testing the null hypothesis that the population RMSEA is no greater than 0.05 . These were all achieved as presented in Table 1.

The descriptive statistics and discriminant validity are presented in Table 2. From the analysis presented, mathematics learning motivation had the highest mean score of 4.427 , whiles performance in mathematics had the least mean score of 4.000 . Since the constructs were measured on a 5-point Likert scale of $1=$ Strongly
Disagree to $5=$ Strongly Agree, the highest possible mean score is 5 . The mean scores as presented in Table 2 were therefore high for all the five variables studied.

There are number of approaches in assessing discriminant validity, but this current study adopts an approach of measuring the square-root of AVEs ( $\sqrt{A V E s}$ ) against the inter-correlation coefficients, as done by past studies such as Bamfo et al. (2018). While convergent validity measures the extent to which measurement items on the same construct correlate with each other, discriminant validity measures the extent to which measurement items are uncorrelated with measurement items on different constructs (Trochim and Donnelly, 2001). The discriminant validity scores were generated along with the CFA output, using the plugin tool available in Amos (v.23). The discriminant validity is said to be achieved when the least $\sqrt{ } \mathrm{AVE}$ is greater than the largest correlation coefficient (Arthur et al., 2021). As presented in Table 2, 0.724 represented the least $\sqrt{ } \mathrm{AVE}$, while 0.661 represented the highest correlation 
Table 2. Descriptive and discriminant validity analysis

\begin{tabular}{lccccccc}
\hline Variables & Mean & Std. Dev. & MOTI & PEER & QUAL & INT & ACHIEV \\
\hline MOTI & 4.427 & 0.575 & $\underline{0.737}$ & & & \\
PEER & 4.086 & 0.688 & $0.653^{* *}$ & $\underline{0.724}$ & & \\
QUAL & 4.138 & 0.702 & $0.580^{* *}$ & $0.606^{* *}$ & $\underline{0.742}$ & \\
INT & 4.285 & 0.935 & $0.511^{* *}$ & $0.547^{* *}$ & $0.574^{* *}$ & $\underline{0.858}$ \\
ACHIEV & 4.000 & 0.699 & $0.590^{* *}$ & $0.602^{* *}$ & $0.661^{* *}$ & $0.556^{* *}$ & $\underline{0.731}$ \\
\hline
\end{tabular}

Note: $\sqrt{ }$ AVE are bold and underlined ${ }^{* *} \mathrm{p}$-value significant at $1 \%(0.01)$

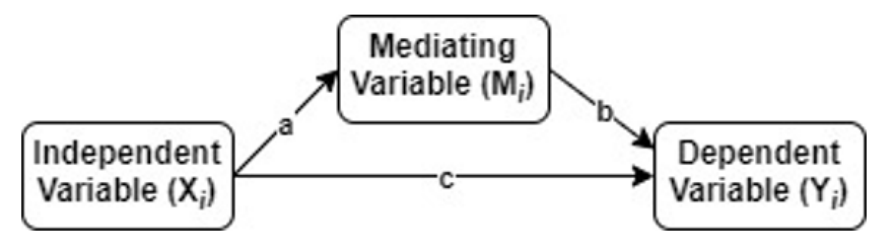

Figure 2. Mediation diagram

coefficient. Discriminant validity was therefore achieved in the dataset.

\section{Mathematical/ Regression Equation}

For a simple mediation model as presented in Figure $2, i^{\text {th }}$ subject $(1 \leq i \leq n)$ is given, as follows:

$$
\begin{gathered}
M_{i}=\alpha+\beta_{a} X_{i}+\varepsilon_{M i} \\
y Y_{i}=\alpha+\beta_{b} M_{i}+\beta_{c} X_{i}+\varepsilon_{Y i}
\end{gathered}
$$

The mathematical equations for the various hypotheses are given, as follows:

H1: Mathematics learning motivation has a direct positive effect on performance in mathematics.

$$
\text { ACHIEV }_{i}=\alpha+\beta_{c 1} \text { MOTI }_{i}+\varepsilon_{\text {ACHIEVi }}
$$

H2: Peer assisted mathematics learning has a direct positive effect on performance in mathematics.

$$
\text { ACHIEV }_{i}=\alpha+\beta_{c 2} \text { PEER }_{i}+\varepsilon_{\text {ACHIEV } i}
$$

H3: Mathematics teaching quality has a direct positive effect on performance in mathematics.

$$
A_{C H I E V_{i}}=\alpha+\beta_{c 3} Q U A L_{i}+\varepsilon_{A C H I E V i}
$$

H4: Mathematics learning interest mediates the relationship between mathematics learning motivation and performance in mathematics.

$$
\begin{gathered}
\text { INT }_{i}=\alpha+\beta_{a 1} \text { MOTI }_{i}+\varepsilon_{I N T i} \\
\text { ACHIEV }_{i}=\alpha+\beta_{b} \text { INT }_{i}+\beta_{c 1} \text { MOTI }_{i}+\varepsilon_{\text {ACHIEVi }}
\end{gathered}
$$

H5: Mathematics learning interest mediates the relationship between peer assisted learning and performance in mathematics.

$$
\begin{gathered}
I^{\prime N T} T_{i}=\alpha+\beta_{a 2} \text { PEER }_{i}+\varepsilon_{I N T i} \\
\text { ACHIEV }_{i}=\alpha+\beta_{b} I N T_{i}+\beta_{c 2} \text { PEER }_{i}+\varepsilon_{\text {ACHIEV } i}
\end{gathered}
$$

H6: Mathematics learning interest mediates the relationship between mathematics teaching quality and performance in mathematics.

$$
\begin{gathered}
I_{N} T_{i}=\alpha+\beta_{a 3} Q_{U A L_{i}}+\varepsilon_{\text {INT } i} \\
\text { ACHIEV }_{i}=\alpha+\beta_{b} \text { INT }_{i}+\beta_{c 3} Q U A L_{i}+\varepsilon_{\text {ACHIEVi }}
\end{gathered}
$$

Overall equations for the study are as follows:

$$
\begin{gathered}
I N T_{i}=\alpha+\beta_{a 1} \text { MOTI }_{i}+\beta_{a 2} \text { PEER }_{i}+\beta_{a 3} Q U A L_{i}+\varepsilon_{I N T i} \\
\text { ACHIEV }_{i}=\alpha+\beta_{b} I N T_{i}+\beta_{c 1} \text { MOTI }_{i}+\beta_{c 2} \text { PEER }_{i}+\beta_{c 3} Q U A L_{i} \\
+\varepsilon_{A C H I E V i}
\end{gathered}
$$

\section{RESULTS}

Structural Equation Modelling (SEM) was run in Amos (v.23) to assess the various paths hypothesized in the study. Bias-Corrected (BC) percentile method of bootstrapping was used, with 5,000 bootstrap sample, and $95 \%$ confidence level. Just like the CFA, the structural model as presented in Table 3 also met the various fit indices as proposed by Hair et al. (2010). Figure 3 also presents the structural model (in diagrammatic form) for the study. Results on the hypothesized paths indicate that mathematics learning motivation had a direct positive effect on performance in mathematics $(\beta=0.937 ; C . R .=5.534)$. That is, about $93.7 \%$ improvement in students' performance in mathematics, when students are fully motivated. H1: Motivation has a direct positive effect on performance in mathematics, was thus supported. Peer assisted learning had positive but statistically insignificant effect on students' performance in mathematics $(\beta=$ 0.043; C. R. = 0.816). H2: Peer learning has a direct positive effect on performance in mathematics, was thus not supported. Mathematics teaching quality had a direct positive effect on students' performance in mathematics $(\beta=0.185 ;$ C. R. $=3.882)$. That is, total mathematics teaching quality increased students' performance in mathematics by about $18.5 \%$. H3: Quality teaching has a direct positive effect on performance in mathematics, was thus supported.

Further, it was found out that mathematics learning motivation had a significant positive effect on students' interest in mathematics $(\beta=1.574$; C. R. = 9.106). That is, when mathematics learning motivation is fully achieved, students' interest in mathematics rises by $157.4 \%$. This represented the highest coefficient recorded in this study, indicating the magnitude of impact that motivation has on students' interest in learning mathematics. Peer assisted learning also had a significant positive effect on students' interest in mathematics $(\beta=0.231 ; \mathrm{C} . \mathrm{R} .=3.153)$. That is, fully engaging in peer assisted learning, increased students' interest in mathematics by $23.1 \%$. Mathematics teaching quality had a significant positive effect on students' 
Table 3. Direct and indirect paths

\begin{tabular}{|c|c|c|c|}
\hline Direct paths & UnStd. estimate & Std. error & C.R. \\
\hline $\mathrm{MOTI} \rightarrow \mathrm{ACHIEV}$ & 0.937 & 0.169 & $5.534^{* *}$ \\
\hline PEER $\rightarrow$ ACHIEV & 0.043 & 0.053 & 0.816 \\
\hline QUAL $\rightarrow$ ACHIEV & 0.185 & 0.048 & $3.882^{* *}$ \\
\hline $\mathrm{INT} \rightarrow \mathrm{ACHIEV}$ & 0.618 & 0.062 & $9.968^{* *}$ \\
\hline $\mathrm{MOTI} \rightarrow \mathrm{INT}$ & 1.574 & 0.173 & $9.106^{* *}$ \\
\hline $\mathrm{PEER} \rightarrow \mathrm{INT}$ & 0.231 & 0.073 & $3.153^{* *}$ \\
\hline QUAL $\rightarrow$ INT & 0.340 & 0.060 & $5.642^{* *}$ \\
\hline Indirect paths & UnStd. estimate & Lower BC & Upper BC \\
\hline$\overline{\mathrm{MOTI}} \rightarrow \mathrm{INT} \rightarrow \mathrm{ACHIEV}$ & 0.973 & 0.019 & 0.528 \\
\hline $\mathrm{PEER} \rightarrow \mathrm{INT} \rightarrow \mathrm{ACHIEV}$ & 0.143 & 0.011 & 0.112 \\
\hline $\mathrm{QUAL} \rightarrow \mathrm{INT} \rightarrow \mathrm{ACHIEV}$ & 0.210 & 0.048 & 0.122 \\
\hline
\end{tabular}

Model fit indices: $C M I N=655.636 ; \quad D F=252 ; \quad C M I N / D F=2.602 ; \quad C F I=0.917 ; \quad T L I=0.925 ; \quad R M R=0.072 ; \quad R M S E A=0.077 ;$ p-close $=0.091$

Bias-corrected (BC) percentile method; 5,000 Bootstrap samples; 95\% Confidence level; ${ }^{* *}$ p-value significant at 1\% (0.01)

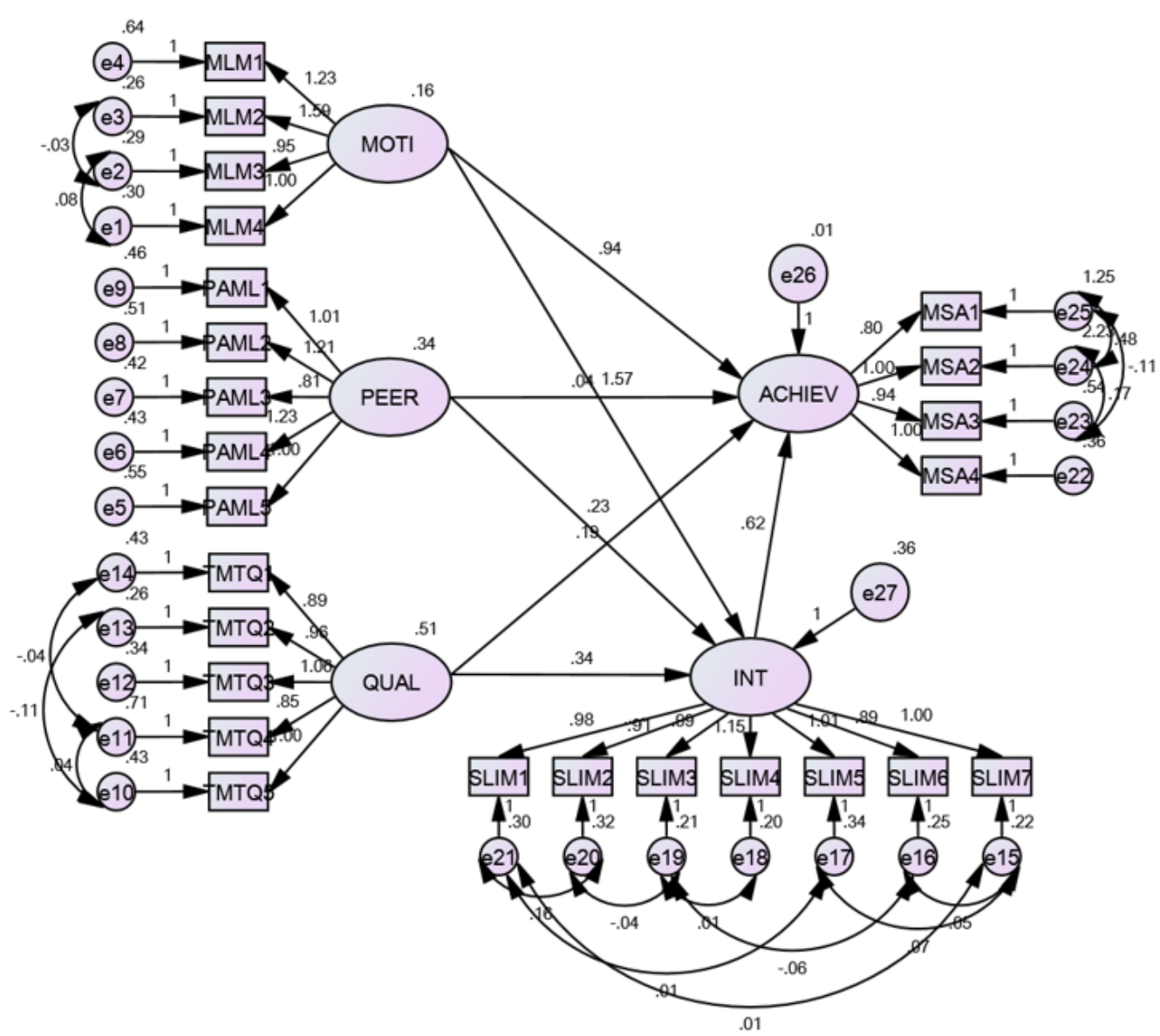

Figure 3. Structural paths

interest in mathematics $(\beta=0.340 ; C . R .=5.642)$. That is, total mathematics teaching quality increased students' interest in mathematics by $34 \%$. Finally, students' interest in mathematics also had a significant positive effect on students' performance in mathematics $(\beta=$ 0.618; C. R. = 9.968). That is, students' interest in mathematics increased students' performance in mathematics by $61.8 \%$.

The study also assessed the mediating effect of students' interest in mathematics. Hypothesis Four (H4) states that student interest mediates the relationship between motivation and performance in mathematics. This was supported by the analysis as the coefficient for the indirect effect of mathematics learning motivation on performance in mathematics (MOTI $\rightarrow$ INT $\rightarrow$ ACHIEV) was 0.973 , and statistically significant (since both the lower and upper BCs were positive). This however represents a partial mediating effect since mathematics learning motivation also had a direct positive effect on students' performance in mathematics. Hypothesis Five (H5) states that student interest mediates the relationship between peer learning and performance in mathematics. This 
was supported by the analysis as the coefficient for the indirect effect of peer assisted learning on performance in mathematics (PEER $\rightarrow$ INT $\rightarrow$ ACHIEV) was 0.143 and statistically significant (since both the lower and upper BCs were positive). Since peer assisted learning had no direct effect on performance in mathematics, it was concluded that students' interest in mathematics played a full mediating role in this relationship. Implying that students' interest in mathematics is a necessary variable if the effect of peer assisted learning on performance in mathematics is to be achieved. Hypothesis Six (H6) states that student interest mediates the relationship between quality teaching and performance in mathematics. This was supported by the analysis as the coefficient for the indirect effect of mathematics teaching quality on performance in mathematics (QUAL $\rightarrow$ INT $\rightarrow$ ACHIEV) was 0.210 , and statistically significant (since both the lower and upper BCs were positive). Since mathematics teaching quality had direct effect on performance in mathematics, it was concluded that students' interest in mathematics played a partial mediating role in this relationship.

\section{DISCUSSION}

Among the university students sampled for the study, it was ascertained that mathematics learning motivation had a significant effect on performance in mathematics of the first-year students. Past studies on mathematics learning motivation have largely focused on basic and secondary level education, with very little attention on the tertiary. This study therefore contributes to literature on mathematics learning motivation at the tertiary level. For example, García et al. (2016) assessed the effect of affective-motivational variables on performance in mathematics in upper elementary levels. Results suggested that, affective-motivational variables accounted for $21.3 \%$ of the variance in performance in mathematics of these upper elementary students. The study found a significant difference in affectivemotivational variables for both high and low performance in mathematics. Habók et al. (2020) looked at the effect of motivation on performance in mathematics among grades 6 and 8 pupils, of which results indicated a significant positive effect. Bringula et al. (2017) also looked at the effects of mathematics learning motivation on students' mathematics performance of grade 7 students. They found out that feedback and motivation significantly predicted mathematics performance of these students. Froiland and Davison (2016) conducted a longitudinal study on the effect of motivation and mathematics course-taking on high school performance in mathematics, among other things. They concluded that mathematics intrinsic motivation in $9^{\text {th }}$ grade significantly influenced student performance in mathematics in $11^{\text {th }}$ grade. Comparing these studies to our current results, we realize that mathematics learning motivation was a significant predictor of performance in mathematics at all levels of education (from basic to tertiary).

Findings also revealed that the effect of mathematics learning motivation on performance in mathematics is not only direct, but partially mediated by mathematics learning interest. Ryan and Deci (2017) considered motivation as an energetic resource generating the needed fuel to persist and successfully accomplish tasks, while Smith et al. (2012) indicated that motivation ignites students' interests in various academic subjects. It is thus clear that mathematics learning motivation builds students' interest in learning mathematics. Among other things, Zhang and Wang (2020) found out that mathematics interest had a direct and positive effect on students' performance in mathematics. Tosto et al. (2016) also found that subject interest had a significant effect on performance in mathematics. This implies that mathematics learning motivation affects students' interest in mathematics, whiles interest in mathematics subsequently affects mathematics study performance of tertiary students. Therefore, although the effect of mathematics study motivation on performance in mathematics could be direct, this effect could also be explained through the mediating effect of mathematics learning interest.

Results from this present study pointed out that peer assisted learning had no significant effect on performance in mathematics among tertiary students. This relationship is contrary to past findings. The influence of social relationships on outcomes in mathematics when using peer tutoring in elementary school has been assessed by Thurston et al. (2020). They found that the perceived cognitive ability of students' mathematics tutoring partner, as well as the trust for the mathematics tutoring partner, had significant positive effect on performance in mathematics. RockinsonSzapkiw and Wendt (2020) assessed the benefits and challenges of a blended peer mentoring program for women peer mentors in science, technology, engineering, and mathematics (STEM). They concluded among other things that, intent to persist in STEM was influenced by the increased mentors' self-efficacy, peer mentoring process, and perceived mentoring skill development. At the secondary education level, Alegre et al. (2019) found that peer tutoring was a significant determinant of performance in mathematics. From these studies, it could be realized that peer assisted learning is very crucial variable in determining the performance of students in mathematics, which this current study failed to establish. Peer assisted learning is a constructive knowledge acquisition approach which happens through social activity (De Lisi \& Golbeck, 1999). Peer assisted learning occurs when a student undertakes the role as a tutor, by teaching his/her classmates who undertake the role of a tutee, with the interaction centered around curriculum content (Ginsburg-Block et al., 2006). 
This present study failed to establish the direct effect of peer assisted learning on performance in mathematics among tertiary students which maybe as a result of some potential facilitating variables in this relationship. Some past studies for example have demonstrated that some variables mediate the relationship between peer assisted learning and mathematics performance of students. In a longitudinal study on the effect of peers on high school performance in mathematics, Froiland and Davison (2016) found out that, mathematics intrinsic motivation mediated the relationship between peer assisted learning and performance in mathematics. Li et al. (2020) also assessed the effect of peer relationships on performance in mathematics in Zhuang adolescents. They identified that motivation mediated the relationship between peer assisted learning and performance in mathematics, whiles the relationship between peer assisted learning and motivation was also moderated by self-efficacy. It is therefore evident that the relationship between peer assisted learning and performance in mathematics, may not just be direct as suggested by some past studies. This present study in line with this, found that mathematics learning interest fully mediated the relationship between peer assisted learning and performance in mathematics. That is, the effect of peer assisted learning on performance in mathematics is realized through the effect of mathematics learning achievement. Peer assisted learning influenced students' mathematics learning interest, whiles interest further influenced performance in mathematics. That is, peer assisted learning which does not result in building students' mathematics learning interest, will have no effect on performance in mathematics of students. Mathematics learning interest is therefore a critical factor, if the effect of peer assisted learning on performance in mathematics is to be realized.

The findings of the present study indicated that mathematics teaching quality has a significant effect on mathematics learning achievement among tertiary students. This is in conformity with some past studies. In science education, Fauth et al. (2019) found that teaching quality had a significant influence on student performance. Cordero and Gil-Izquierdo (2018) found that traditional teaching methods had a positive significant effect on student achievement in mathematics, while innovative active learning strategies had a negative significant on student achievement in mathematics. In Ghana, teacher factors were found to positively affect students' performance (Azigwe et al., 2016). From these studies, vis-à-vis our current finding, we realize that teaching quality dimensions (classroom management, supportive climate and cognitive activation) cumulatively influenced student's academic performance, and mathematics learning achievement is no exception.
Findings from this present study further revealed that the effect of mathematics teaching quality on tertiary students' performance in mathematics was not only direct, but also mediated through mathematics learning interest. In mathematics education, Lazarides and Buchholz (2019) found that perceived teaching quality influenced diverse student achievement emotions. Similarly, in science education, Fauth et al. (2019) found that teaching quality had a significant influence on students' interest. Arthur (2019) and Arthur et al. (2017) also found that constructivists teaching method and teacher-student variables significantly influenced students' interest in mathematics. The effect of interest on performance in mathematics has also been well established (Fauth et al., 2019; Lazarides et al., 2021). This indicates that mathematics learning interest potentially explained the effect of teaching quality on performance in mathematics. Tosto et al. (2016) in their study also found that subject interest mediated the relationship between classroom environment and mathematics learning achievement among students. That is, mathematics teaching quality influenced tertiary students' interest in learning mathematics, while mathematics learning interest had a significant influence on mathematics learning achievement.

The novelty of this study focused on the mediating role of student interest among the various direct relationships, as this was not well-established in available literature. There are available studies on the direct effect of learning motivation on performance in mathematics; effect of peer assisted learning mathematics performance; and the effect of teaching quality on performance in mathematics. This present study contributed to existing knowledge by presenting students' learning interest as a potential intervening variable among these direct effects or relationship. Another key novelty of the study was the identification that the effect of peer assisted learning on performance in mathematics was not direct, but fully explained or mediated through students' learning interest.

\section{CONCLUSIONS}

The study concluded that mathematics learning motivation and mathematics teaching quality had significant positive effects on performance in mathematics among tertiary students. Peer assisted mathematics learning, however, had no direct effect on mathematics learning achievement. The relationship was rather mediated fully by students' learning interest in mathematics. The effects of mathematics learning motivation and mathematics teaching quality on performance in mathematics were also partially mediated by students' interest in mathematics. 


\section{Recommendations}

It was recommended to management of higher learning institutions to pay particular attention to the three dimensions of teaching quality, which were classroom management, supportive climate and cognitive activation. Classroom management refers to the classroom procedures and rules, smooth transitions and coping with disruptions. Supportive climate, which is sometimes referred to as teacher support, represents the specific aspects of teacher-student interactions such as teacher feedback (which must be positive, individualized, and constructive), positive attitude towards student errors, and a caring teacher behavior. Cognitive activation refers to the system of challenging students' notions through a teacher-guided classroom discussion. This is achieved through the provision of challenging assignments, experiments, observations, etc. with the aim to cognitively engage with the educational content. Management must also create the needed environment for peer assisted learning, and should also put in place some external motivation mechanisms.

\section{Limitations}

The following recommendation is made for future studies. Teaching quality is classified into three dimensions (classroom management, supportive climate and cognitive activation), while interest is also divided into two major forms (situational and individual/dispositional). This study however focused on the higher-order variables (teaching quality and learning interest), without specific attention on the firstorder variables. Focusing specific attention on the firstorder variables may have provided different perspective to the results attained, and this could therefore be the focus of future studies.

Author contributions: All authors have sufficiently contributed to the study, and agreed with the results and conclusions.

Funding: No funding source is reported for this study.

Declaration of interest: No conflict of interest is declared by authors.

\section{REFERENCES}

Abreh, M. K., Owusu, K. A., \& Amedahe, F. K. (2018). Trends in performance of WASSCE candidates in the science and mathematics in Ghana: Perceived contributing factors and the way forward. Journal of Education, 198(1), 113-123. https://doi.org/ $10.1177 / 0022057418800950$

Alegre, F., Moliner, L., Maroto, A., \& Lorenzo-Valentin, G. (2019). Peer tutoring and mathematics in secondary education: Literature review, effect sizes, moderators, and implications for practice. Heliyon, 5(9), e02491. https://doi.org/10.1177/ 0022057418800950

Arthur, D. Y. (2019). Effect of the constructivists teaching method, undergraduate students' statistics self- concept and other psychological constructs in mediating their motivation for learning statistics. African Journal of Educational Studies in Mathematics and Sciences, 15(1), 129-142. https://doi.org/ 10.1016/j.heliyon.2019.e02491

Arthur, Y. D., Asiedu-Addo, S., \& Assuah, C. (2017). Teacher-student variables as predictor of students' interest in mathematics: The use of stepwise multiple linear regression analysis. Asian Research Journal of Mathematics, 4(3), 1-11. https://doi.org/ 10.9734/ARJOM/2017/33544

Arthur, Y. D., Dogbe, C. S. K., \& Asiedu-Addo, S. K. (2021). Modeling students' mathematics achievement and performance through teaching quality: SERVQUAL perspective. Journal of Applied Research in Higher Education. https://doi.org/ 10.1108/JARHE-06-2021-0243

Azigwe, J. B., Kyriakides, L., Panayiotou, A., \& Creemers, B. P. (2016). The impact of effective teaching characteristics in promoting student achievement in Ghana. International Journal of Educational Development, 51, 51-61. https:/ / doi.org/10.1016/j.ijedudev.2016.07.004

Bamfo, B. A., Dogbe, C. S. K., \& Mingle, H. (2018). Abusive customer behaviour and frontline employee turnover intentions in the banking industry: The mediating role of employee satisfaction. Cogent Business \& Management, 5(1), 115.

https:/ / doi.org/10.1080/23311975.2018.1522753

Bezzina, F. H. (2010). Investigating gender differences in mathematics performance and in self-regulated learning. Equality, Diversity and Inclusion: $A n$ International Journal, 29(7), 669-693. https:/ / doi.org/10.1108/02610151011074407

Bringula, R., De Leon, J. S., Rayala, K. J., Pascual, B. A., \& Sendino, K. (2017). Effects of different types of feedback of a mobile-assisted learning application and motivation towards mathematics learning on students' mathematics performance. International Journal of Web Information Systems, 13(3), 241-259. https:/ / doi.org/10.1108/IJWIS-03-2017-0017

Cordero, J. M., \& Gil-Izquierdo, M. (2018). The effect of teaching strategies on student achievement: An analysis using TALIS-PISA-link. Journal of Policy Modeling, 40(6), 1313-1331. https://doi.org/ 10.1016/j.jpolmod.2018.04.003

De Lisi, R., \& Golbeck, S. (1999). Implications of piagetian theory for peer learning. Mahway. https:/ / books.google.com.gh/books?hl=en\&lr=\&i $\mathrm{d}=7$ ZRAwAAQBAJ\&oi=fnd\&pg $=$ PA3\&dq $=\mathrm{De}+\mathrm{L}$ isi,+R.,+\%26+Golbeck,+S.+(1999).+Implications+of +piagetian+theory+for+peer+learning.+Mahway. \&ots=foPWaWJGK3\&sig=yfTa 4 z6h3nJciLhF95Arfa2jGI\&redir_esc $=\mathrm{y} \# \mathrm{v}=$ onepage\&q\&f=false 
Diaconu-Gherasim, L. R., Măirean, C., \& Brumariu, L. E. (2019). Quality of teachers' and peers' behaviors and achievement goals: The mediating role of selfefficacy. Learning and Individual Differences, 73, 147156. https:/ / doi.org/10.1016/j.lindif.2019.06.001

Dinkelmann, I., \& Buff, A. (2016). Children's and parents' perceptions of parental support and their effects on children's achievement motivation and achievement in mathematics. A longitudinal predictive mediation model. Learning and Individual Differences, 50, 122-132. https://doi.org/10.1016/ j.lindif.2016.06.029

Dogbe, C. S. K., Tian, H., Pomegbe, W. W. K., Sarsah, S. A., \& Otoo, C. O. A. (2020). Effect of network embeddedness on innovation performance of small and medium-sized enterprises. Journal of Strategy and Management, 13(2), 181-197. https://doi.org/ 10.1108/JSMA-07-2019-0126

Dorfner, T., Förtsch, C., \& Neuhaus, B. J. (2018). Effects of three basic dimensions of instructional quality on students' situational interest in sixth-grade biology instruction. Learning and Instruction, 56, 42-53. https:/ / doi.org/10.1016/j.learninstruc.2018.03.001

Ersozlu, Z., Usak, M., \& Blake, D. (2021). Using multigroup invariance analysis in exploring crosscultural differences in mathematics anxiety: A comparison of Australia and Russia. Journal of Ethnic and Cultural Studies, 9(1), 1-18. https:// doi.org/10.29333/ejecs/987

Fauth, B., Decristan, J., Decker, A. T., Buettner, G., Hardy, I., Klieme, E., \& Kunter, M. (2019). The effects of teacher competence on student outcomes in elementary science education: The mediating role of teaching quality. Teaching and Teacher Education, 86, 102882. https://doi.org/10.1016/ j.tate.2019.102882

Fornell, C., \& Larcker, D. F. (1981). Evaluating structural equation models with unobservable variables and measurement error. Journal of Marketing Research, 18(1), 39-50. https:/ / doi.org/10.1177/00222437810 1800104

Froiland, J. M., \& Davison, M. L. (2016). The longitudinal influences of peers, parents, motivation, and mathematics course-taking on high school math achievement. Learning and Individual Differences, 50, 252-259. https://doi.org/10.1016/j.lindif.2016.07. 012

García, T., Rodríguez, C., Betts, L., Areces, D., \& González-Castro, P. (2016). How affectivemotivational variables and approaches to learning predict performance in mathematics in upper elementary levels. Learning and Individual Differences, 49, 25-31. https://doi.org/10.1016/ j.lindif.2016.05.021
Ginsburg-Block, M. D., Rohrbeck, C. A., \& Fantuzzo, J. W. (2006). A meta-analytic review of social, selfconcept, and behavioral outcomes of peer-assisted learning. Journal of Educational Psychology, 98(4), 732-749. https://doi.org/10.1037/0022-0663.98.4. 732

Habók, A., Magyar, A., Németh, M. B., \& Csapó, B. (2020). Motivation and self-related beliefs as predictors of academic achievement in reading and mathematics: Structural equation models of longitudinal data. International Journal of Educational Research, 103, 101634. https://doi.org/10.1016/ j.ijer.2020.101634

Hair, J. F., Black, W. C., Babin, B. J., \& Anderson, R. E. (2010). Multivariate data analysis: A global perspective (7th Ed.). Pearson Education. https://www. pearson.com/uk/educators/higher-educationeducators/program/Hair-Multivariate-DataAnalysis-Global-Edition-7thEdition/PGM916641.html

Hinnant-Crawford, B. N., Faison, M. Z., \& Chang, M. L. (2016). Culture as mediator: Co-regulation, selfregulation, and middle school performance in mathematics. Journal for Multicultural Education, 10(3), 274-293. https://doi.org/10.1108/JME-052016-0032

Huang, C. S., Su, A. Y., Yang, S. J., \& Liou, H. H. (2017). A collaborative digital pen learning approach to improving students' learning achievement and motivation in mathematics courses. Computers $\mathcal{E}$ Education, 107, 31-44. https://doi.org/10.1016/ j.compedu.2016.12.014

Hwang, G. J., Wang, S. Y., \& Lai, C. L. (2021). Effects of a social regulation-based online learning framework on students' learning achievements and behaviors in mathematics. Computers $\mathcal{E}$ Education, 160, 104031. https:// doi.org/10.1016/j.compedu.2020.104031

Hyman, L., Lamb, J., \& Bulmer, M. (2006, April). The use of pre-existing survey questions: Implications for data quality. In Proceedings of the European Conference on Quality in Survey Statistics (pp. 1-8). Cardiff. https://www.researchgate.net/profile/ Nasir-Ali-22/post/Writing-a-survey/attachment/ 59d6467e79197b80779a1843/AS\%3A458354666545 $154 \% 401486291676321 /$ download/The+Use + of $+\mathrm{P}$ re-Existing+Survey+Questions.pdf

Korhonen, J., Tapola, A., Linnanmäki, K., \& Aunio, P. (2016). Gendered pathways to educational aspirations: The role of academic self-concept, school burnout, achievement and interest in mathematics and reading. Learning and Instruction, 46, 21-33. https://doi.org/10.1016/j.learninstruc. 2016.08.006

Lahey, B. B., McNealy, K., Knodt, A., Zald, D. H., Sporns, O., Manuck, S. B., ... \& Hariri, A. R. (2012). Using confirmatory factor analysis to measure 
contemporaneous activation of defined neuronal networks in functional magnetic resonance imaging. Neuroimage, 60(4), 1982-1991. https:// doi.org/10.1016/j.neuroimage.2012.02.002

Lazarides, R., \& Buchholz, J. (2019). Student-perceived teaching quality: How is it related to different achievement emotions in mathematics classrooms? Learning and Instruction, 61, 45-59. https:// doi.org/10.1016/j.learninstruc.2019.01.001

Lazarides, R., Fauth, B., Gaspard, H., \& Göllner, R. (2021). Teacher self-efficacy and enthusiasm: Relations to changes in student-perceived teaching quality at the beginning of secondary education. Learning and Instruction, 73, 101435. https:/ / doi.org /10.1016/j.learninstruc.2020.101435

Lerkkanen, M. K., Kiuru, N., Pakarinen, E., Viljaranta, J., Poikkeus, A. M., Rasku-Puttonen, H., Siekkinen, M., \& Nurmi, J. E. (2012). The role of teaching practices in the development of children's interest in reading and mathematics in kindergarten. Contemporary Educational Psychology, 37(4), 266-279. https:// doi.org/10.1016/j.cedpsych.2011.03.004

Li, L., Peng, Z., Lu, L., Liao, H., \& Li, H. (2020). Peer relationships, self-efficacy, academic motivation, and performance in mathematics in Zhuang adolescents: A moderated mediation model. Children and Youth Services Review, 118, 105358. https://doi.org/10.1016/j.childyouth.2020.105358

Miller, R. L., \& Brewer, J. D. (2003). The AZ of social research: a dictionary of key social science research concepts. SAGE. https://books.google.com/books? $\mathrm{hl}=\mathrm{en} \& \mathrm{r}=\& \mathrm{id}=\mathrm{q} 8-\mathrm{QD}-\mathrm{y} 2 \mathrm{k} 20 \mathrm{C} \& \mathrm{oi}=\mathrm{fnd} \& \mathrm{pg}=\mathrm{PP} 2 \&$ dq $=$ Miller,,+ R.+L., + \%26+Brewer, + J.+D.+(2003).+T he+AZ+of+social+research:+a+dictionary+of + key + social+science+research+concepts.+SAGE.\&ots=J h_13kCD13\&sig=CGkU028658SEL5zBnWNDS0v4 MFY

Motegi, H., \& Oikawa, M. (2019). The effect of instructional quality on student achievement: Evidence from Japan. Japan and the World Economy, 52, 100961. https:/ / doi.org/10.1016/j.japwor.2019. 100961

Nauzeer, S., \& Jaunky, V. C. (2021). A meta-analysis of the combined effects of motivation, learning and personality traits on academic performance. Pedagogical Research, 6(3), em0097. https:/ / doi.org/ $10.29333 / \mathrm{pr} / 10963$

Pitsia, V., Biggart, A., \& Karakolidis, A. (2017). The role of students' self-beliefs, motivation and attitudes in predicting performance in mathematics: A multilevel analysis of the programme for international student assessment data. Learning and Individual Differences, 55, 163-173. https:// doi.org/10.1016/j.lindif.2017.03.014
Prast, E. J., Van de Weijer-Bergsma, E., Miočević, M., Kroesbergen, E. H., \& Van Luit, J. E. (2018). Relations between performance in mathematics and motivation in students of diverse achievement levels. Contemporary Educational Psychology, 55, 8496. https://doi.org/10.1016/j.cedpsych.2018.08. 002

Reeve, J., Lee, W., \& Won, S. (2015). Interest as emotion, as affect, as schema. In K. A. Renninger, M. Nieswandt, \& S. Hidi (Eds.), Interest in mathematics and science learning (pp. 79-92). American Educational Research Association. https:// doi.org/10.3102/978-0-935302-42-4_5

Rockinson-Szapkiw, A., \& Wendt, J. L. (2020). The benefits and challenges of a blended peer mentoring program for women peer mentors in science, technology, engineering and mathematics (STEM). International Journal of Mentoring and Coaching in Education, 10(1), 1-16. https:/ / doi.org/ 10.1108/IJMCE-03-2020-0011

Röllke, K., Maak, A. L., Wenzel, A., \& Grotjohann, N. (2020). Experimental workshops in student labs and at school--What influence do location and personality traits have on learners' motivational variables? Pedagogical Research, 5(1), em0050. https:// doi.org/10.29333/pr/6338

Ryan, R. M., \& Deci, E. L. (2017). Self-determination theory: Basic psychological needs in motivation, development, and wellness. Guilford Publications. https:// doi.org/10.1521/978.14625/28806

Saunders, M., Lewis, P., \& Thornhill, A. (2012). Research methods for business students. Pearson Education Ltd., Harlow. https://www.pearson.com/uk/ educators/higher-education-educators / product/ Saunders-Saunders-Research-Methods-for-Bu-p-66th-Edition/9780273750758.html

Skaalvik, E. M., Federici, R. A., \& Klassen, R. M. (2015). Performance in mathematics and self-efficacy: Relations with motivation for mathematics. International Journal of Educational Research, 72, 129136. https:/ / doi.org/10.1016/j.ijer.2015.06.008

Smith, J. K., Smith, L. F., Gilmore, A., \& Jameson, M. (2012). Students' self-perception of reading ability, enjoyment of reading and reading achievement. Learning and individual differences, 22(2), 202-206. https:/ / doi.org/10.1016/j.lindif.2011.04.010

Surur, A. M. (2022). Application of monopoly media to improve readiness for class VI students in facing the national examination of mathematics learning. International Journal of Pedagogical Development and Lifelong Learning, 4(1), ep2201. https://doi.org/ 10.30935/ijpdll/11419

Syarifuddin, H., \& Atweh, B. (2022). The use of activity, classroom discussion, and exercise (ACE) teaching cycle for improving students' engagement in 
learning elementary linear algebra. European Journal of Science and Mathematics Education, 10(1), 104-138. https:/ / doi.org/10.30935/scimath/11405

Thurston, A., Roseth, C., Chiang, T. H., Burns, V., \& Topping, K. J. (2020). The influence of social relationships on outcomes in mathematics when using peer tutoring in elementary school. International Journal of Educational Research Open, 1, 100004.

https:/ / doi.org/10.1016/j.ijedro.2020.100004

Tosto, M. G., Asbury, K., Mazzocco, M. M., Petrill, S. A., \& Kovas, Y. (2016). From classroom environment to performance in mathematics: The mediating role of self-perceived ability and subject interest. Learning and Individual Differences, 50, 260-269. https://doi.org/10.1016/j.lindif.2016.07.009

Trochim, W. M., \& Donnelly, J. P. (2001). Research methods knowledge base (Vol. 2). Atomic Dog Publishers. https:/ / www.researchgate.net/profile/WilliamTrochim/publication/243783609_The_Research_ Methods_Knowledge_Base/links/55db837008aed
6a199ac6246/The-Research-Methods-KnowledgeBase.pdf

Xia, Y., \& Yang, Y. (2019). RMSEA, CFI, and TLI in structural equation modeling with ordered categorical data: The story they tell depends on the estimation methods. Behavior Research Methods, 51(1), 409-428. https://doi.org/10.3758/s13428018-1055-2

Zhang, D., \& Wang, C. (2020). The relationship between mathematics interest and performance in mathematics: mediating roles of self-efficacy and mathematics anxiety. International Journal of Educational Research, 104, 101648. https:/ / doi.org/ 10.1016/j.ijer.2020.101648

Zhou, D., Liu, J., \& Liu, J. (2020). The effect of problematic Internet use on performance in mathematics: The mediating role of self-efficacy and the moderating role of teacher-student relationships. Children and Youth Services Review, 118, 105372. https://doi.org/10.1016/j.childyouth. 2020.105372

\section{https://www.ejmste.com}

